\title{
De pánicos sexuales y sus legados represivos
}

\author{
DEBORAH DAICH* \\ Doctora en Antropología por la Universidad de Buenos Aires. \\ CONICET. Colectiva de Antropólogas Feministas. \\ IIEG- UBA \\ deborahdaich@yahoo.com.ar
}

\section{Resumen}

El discurso del combate a la trata ha servido como vehículo para un pánico sexual que claramente la excede, todo lo que se conecte con el mercado del sexo es pasible de ser leído en clave de "esclavitud" y pura violencia, pura explotación, y ha comenzado así una cruzada moral salvacionista que no complejiza, no explica ni describe los fenómenos, sino que los valoran y los juzgan. Así, lo que hoy está en el ojo de la tormenta es el sexo comercial y las mismas definiciones de sexualidad.

Me propongo seguir la propuesta de Janice Irvine (2006), quien señala algunas características o recurrencias de la retórica de los pánicos sexuales. Así, pretendo delinear los pánicos sexuales construidos en torno a la trata de personas con fines de explotación sexual y al mercado del sexo atendiendo a sus legados represivos y de estigmatización.

Palabras claves: pánico sexual, prostitución, política

\section{Abstract}

The anti-trafficking discourse has served as a vehicle for sex panics. Because all that is connected with the sex trade is liable to be read in terms of "slavery" and pure violence, a Salvationist moral crusade has been started and this crusade does not describe nor explain the phenomena, it only judges it. So, what is actually on focus is the commercial sex and the definitions of sexuality.

I intend to follow the proposal of Janice Irvine (2006) who pointed out some features or recurrences of the rhetoric of sexual panics. So, I intend to outline the sexual panics built around human trafficking for sexual exploitation and around the sex market. I also pay attention to the panic's repressive and stigmatizing legacies.

Key words: sex panics, prostitution, politics

Daich, Deborah "De pánicos sexuales y sus legados represivos", en Zona Franca. Revista del Centro de Estudios Interdisciplinario sobre Mujeres, Año XXI, № 22, 2013, pp. 31-40.

Recibido: 30 de agosto - Aceptado: 11 de octubre 2013 


\section{De pánicos morales a pánicos sexuales}

n los años 70 Stanley Cohen publicó un libro Folk devils and Moral Panics - algo así como "Demonios populares y pánicos morales"- un trabajo hasta hoy muy influyente en las ciencias sociales. Acuñó entonces el término "Pánico moral"1 que le sirvió para dar cuenta de cómo el comportamiento desviado es construido socialmente (no hay que olvidar que Cohen estaba discutiendo entonces con la criminología clásica). Decía Cohen:

Las sociedades parecen estar sujetas, de vez en cuando, a períodos de pánico moral. Una condición, episodio, persona o grupo de personas emerge para ser definida como una amenaza a los valores e intereses de la sociedad, su naturaleza se presenta de una forma estilizada y estereotipada por los medios de comunicación, las barricadas morales están a cargo de los editores, obispos, políticos y otras personas bien pensantes; expertos socialmente acreditados anuncian diagnósticos y soluciones (...) A veces el objeto del pánico es bastante original y en otras ocasiones se trata de algo de larga data que de repente aparece en el centro de la atención. A veces el pánico pasa y se olvida, excepto en el folclore y la memoria colectiva, y otras veces tiene repercusiones más graves y de larga duración y puede producir cambios tales como los de la política jurídica y social o incluso en la forma en que la sociedad se concibe a sí misma. (Cohen 2002 [1972]: 1). ${ }^{2}$

El pánico moral describe la erupción o ebullición social (el "clima" social) que transforma a un grupo marginal en un demonio popular o en grupo desviado; describe configuraciones sociales que tienen la habilidad para demonizar públicamente a un grupo y a sus prácticas. La parte moral del asunto viene con la condena y la desaprobación social, la valoración en términos de lo que es bueno o malo para los valores e intereses de una sociedad. El pánico, a su vez, es más bien una metáfora para hablar del elemento emocional que acompaña la erupción social, para hablar del lenguaje emocional activado en discursos públicos, algunos rayanos en la histeria y la exageración. Claro que esta parte emotiva del fenómeno no ha de verse como irracionalidad ni como expresión de una pretendida homogeneidad moral, algunas autoras han trabajado ya sobre los guiones emocionales de los pánicos morales y sexuales como eventos políticos (Irvine, 2000; 2006). En el caso de Cohen, cuando escribió el libro fue para ocuparse de lo que él veía como el pánico social más recurrente en la Gran Bretaña del momento: las nuevas culturas juveniles (principalmente de clase trabajadora) cuyas conductas eran vistas como desviadas o asociadas al delito y, en su mayor parte, como "violentas" (the mods \& the rockers).

Los pánicos morales dejan efectos concretos, la mayoría de las veces prejuicios y discriminaciones grabadas a fuego en la memoria colectiva pero también legislaciones represivas. Basta con pensar, por ejemplo, el lugar que ha ocupado en los últimos debates sobre "(in)seguridad" la construcción de los "pibes chorros". Cada vez que se sucede un hecho violento en el que aparece un menor involucrado empieza un debate político, atizado por los medios, en los que aparecen recursos argumentales que apelan a las emociones (compasión e indignación) e imágenes fuertes como "niños con licencia para matar" (sic); se exageran los casos, se enfatiza el peligro y se demonizan a los niños pobres: "drogadictos que no tienen nada que perder" (sic) y entonces empiezan las discusiones públicas sobre la edad de imputabilidad.

En los años 80, la antropóloga feminista Carole Vance, inspirándose en la obra de Cohen, acuñó el término "pánico sexual" para describir y examinar conflictos y controversias públicas en relación con asuntos sexuales. En realidad, Vance utilizó primero la idea de pánico sexual para describir los sucesos acontecidos durante la famosa Barnard Conference sobre sexualidad de $1982^{3}$.

Así, desde los años 1980, pánico sexual -como concepto y como metáfora- comenzó a ser usado por autores como Gayle Rubin, Jeffrey Weeks, Lisa Duggan, Nan Hunter, entre tantas. Gayle Rubin, por ejemplo, trabajó sobre los pánicos en su famoso Reflexionando sobre el sexo pero utilizó concretamente el término para hablar -para Estados Unidos- de la campaña anti-homosexual de los años 50 , en pleno mccarthismo, y luego también (los entrampment en baños públicos y el uso de leyes de sodomía).

Pánicos sexuales se suceden una y otra vez, por ejemplo, cuando se habla de educación sexual integral, sobre todo en las escalas locales. Janice Irvine (2006) ha dado cuenta para Estados Unidos cómo, desde los años 60 en adelante, cada vez que se trata de debatir programas de educación sexual, las comunidades educativas empiezan a bullir. Para nuestro país, cabe recordar todas las trabas que impuso la Iglesia Católica para impedir que se legislara sobre el programa nacional de Educación Sexual Integral (ESI) y cómo, aliada a conservadores 
varios, sigue impidiendo su práctica. Los primeros manuales dirigidos a docentes del programa ESI (como el Material de formación de formadores en educación sexual y prevención del VIH/Sida 2009) fueron calificados por monseñor Aguer (apoyado por el entonces cardenal Bergoglio) como una imposición "totalitaria y neomarxista" donde "la ideología de género se expresa en este documento con el máximo rigor" y se presenta "como el instrumento para modificar significados y prácticas". Decía también Aguer de estos manuales: "jamás se habla de amor. El sexo, al parecer, no tiene nada que ver con el amor"4.

La utilización de algunos argumentos falsos (como que el uso del condón no previene el contagio del HIV), y de otros simplemente ideológicos, fueron retomados por distintos detractores para inflamar contiendas cuasi-sangrientas en las escuelas. El movimiento "Salvemos la familia" de la provincia de San Juan, por ejemplo, contando con estos argumentos de la iglesia inició, en el 2011, una campaña para rechazar la educación sexual en las escuelas; actividad que ha tomado el nombre de "Campaña por el NO a la ideología de género en las escuelas". También en la provincia de Formosa se dieron acontecimientos semejantes. A fines del año 2012, por ejemplo, se acusó a un docente de exhibir un video pornográfico a jóvenes de 14 años y, luego de la presión de padres y madres, curia local y medios, fue separado preventivamente de su cargo. Era un video sobre el uso del preservativo explicado por una profesional y sin imágenes reales del cuerpo humano.

El movimiento anti-pornografía en Estados Unidos de los años 80 también puede leerse como pánico sexual y como una cruzada moral que aunó, curiosamente, a feministas con religiosos y políticos de derecha. En los años 70, algunas feministas norteamericanas formaron Women against Violence in Pornography and Media (WAVPM) y otras se agruparon en Women Against Violence Against Women (WAVAW), agrupaciones que lucharon en contra de las imágenes violentas y vejatorias respecto de las mujeres en los medios. Algunas de las mujeres que conformaban estas agrupaciones junto con otras conformaron luego Women Against Pornography (WAP) -la que más adelante se re convertirá en la Coalition Against Trafficking in Women (CATW)- y con esta agrupación comenzó una verdadera cruzada en contra de la pornografía y casi toda imagen sexual. Estas organizaciones emprendieron campañas varias en contra de la pornografía, entendiéndola como violencia contra las mujeres ("la pornografía es la teoría, la violación es la práctica", al decir de la feminista Robin Morgan) y, a través de Catherine Mackinnon y Andrea Dworkin impulsaron ordenanzas que prohibían la pornografía. Indianápolis fue la primera ciudad en firmar dicha ley pero no duró ni una hora porque fue desestimada al denunciarse que violaba la $1^{\circ}$ enmienda norteamericana, la libertad de expresión. Había sido sostenida por asociaciones vecinales, republicanos conservadores, fundamentalistas de derecha y miembros de una coalición norteamericana que lleva un nombre más que sugerente: Mayoría Moral.

Como muestran Lisa Duggan y Nan Hunter (2006), el movimiento antipornografía preparó el terreno para iniciativas conservadoras para eliminar subsidios al arte erótico- por ejemplo, cuando en el año 1989 el Corcoran (el museo de arte de Washington) suspendió la muestra de Robert Mapplethorpe. Y en el año 1990 el director del museo de arte contemporáneo de Cincinnati tuvo que enfrentar cargos "por uso de material obsceno" debido a una exhibición de fotos del mismo artista.

Así pues, pánico sexual refiere a una forma específica del pánico moral con el que referirnos a conflictos públicos sobre sexualidad y moral sexual. Y me parece que hoy el discurso del combate a la trata ha servido como vehículo para un pánico sexual que claramente la excede. Todo lo que se conecte con el mercado del sexo es pasible de ser leído en clave de "esclavitud" y pura violencia, pura explotación, y ha comenzado así una cruzada moral salvacionista que no complejiza, no explica ni describe los fenómenos sino que los valoran y los juzgan. Así, lo que hoy está en el ojo de la tormenta es el sexo comercial y las mismas definiciones de sexualidad.

\section{Pánicos sexuales y sexo comercial}

Janice Irvine (2006) señala algunas características o recurrencias de la retórica de los pánicos sexuales que me parece importante recuperar para nuestra coyuntura actual. Así, me propongo seguir su propuesta para delinear los pánicos sexuales construidos en torno a la trata de personas con fines de explotación sexual y al mercado del sexo. En primer lugar, Irvine señala que los discursos emocionales públicamente accionados en estos pánicos sexuales suelen enfatizar el peligro.

Se puede ejemplificar esta característica a partir del dis- 
curso público de tipo "Vos podés ser la próxima víctima", consigna que ha estado presente en varias manifestaciones en contra de la trata de personas con fines de explotación sexual así como en marchas de colectivos feministas y no feministas, que ha formado parte de una campaña gráfica de la Dirección Nacional de Migraciones ${ }^{5}$ y que, inclusive, da nombre a una página de Facebook.

"Vos podes ser la próxima víctima. No seas un nuevo cliente" fue la consigna de la Multisectorial de Mujeres de Cutral-Co el 23 de septiembre del año 2012. Casualmente, la consigna "vos podés ser la próxima víctima" es la que utilizó el adalid de la "mano dura" Juan Carlos Blumberg ${ }^{6}$ en sus últimas marchas contra la inseguridad.

Recurrentemente en las redes sociales aparecen recomendaciones para que las mujeres no circulen solas por las calles ante la posibilidad de ser secuestradas violentamente. $Y$ casi cualquier denuncia de un hecho violento en la calle (robo, intento de secuestro o abuso, etc.) es leído por muchos medios de comunicación en clave de intento de secuestro con fines de explotación sexual. En la misma línea, muchos cuadernillos institucionales de prevención de la trata de personas traen recomendaciones tales como "no vayas sola a entrevistas de trabajo". ${ }^{7}$ Esta retórica que enfatiza el peligro tiene como contrapartida ni más ni menos que la reducción de la libre circulación de las mujeres.

En segundo lugar, Irvine (2006) señala que esta retórica generalmente hace un uso de datos falsos o no comprobados. Para el caso en cuestión, hay que señalar que las estadísticas respecto de las mujeres "rescatadas" de las redes de trata no son confiables y en cuanto a las de las "desaparecidas", menos aun (Varela, 2011 y 2013). Sin embargo, cifras alarmantes respecto de estas mujeres circulan continuamente en los medios masivos de comunicación generando un clima social de preocupación y temor ${ }^{8}$.

Así, los pánicos replican narrativas poco comprobadas que terminan por volverse leyendas urbanas:

Hace diez días, un comunicado de prensa del Bloque de la Coalición Cívica, con la firma de la diputada Fernanda Gil Lozano dio un alerta "a partir del importante incremento del número de denuncias recibidas en mi despacho durante los últimos meses, vinculadas con intentos de secuestros de chicas jóvenes y adolescentes en el barrio de Monserrat y Constitución". El comunicado afirmó que en esos barrios y "sobre todo en la avenida San Juan, por la noche, está circulando una camioneta de la que desciende un hombre que posee las siguientes características: mide 1,80 metro de estatura, tiene ojos azules y está encapuchado. Su modo de actuar, acorde con las descripciones, consiste en descender de la camioneta, dejar la puerta lateral trasera abierta, sujetar a su víctima por el brazo e intentar adormecerla por medio de una trompada. En ocasiones, va en una camioneta azul metalizada tipo Kangoo, conducida por una mujer. En otras, usa una trafic blanca".

Página/12 consultó a la diputada al respecto y precisó que el "importante incremento del número de denuncias" hacía referencia a "tres" denuncias de adolescentes de entre 17 y 18 años "de carne y hueso". Gil Lozano defendió la veracidad de las denuncias. El problema -objetó- es que "no les tomen las denuncias en las comisarías. Porque no les creen". "Si en la Capital Federal pasa eso me imagino que lo mismo sucederá en el conurbano, por eso no quedan registrado estos casos", consideró. Una de ellas hizo la denuncia en la Ufase. "No me dio la sensación de que estuvieran mintiendo", agregó.

(...)

"Es una mentira absoluta. No existe ningún caso real. Es una leyenda urbana que alimentan aquellos que fogonean el pánico", aseguró a Página/12 Cristina Fernández, directora del Registro Nacional de Personas Menores Extraviadas, que depende del Ministerio de Justicia y Derechos Humanos. "Podrá haber algún caso aislado de secuestro para explotación sexual. Pero no hay un patrón que se repite. Es un rumor que está dando vueltas desde hace seis años", afirmó Zaida Gatti. ${ }^{9}$ (Nota de Mariana Carbajal Página 12, 4/9/2011)

Los pánicos sexuales se expresan a través de narrativas chocantes y de un lenguaje sexual explícito y exagerado (Irvine, 2006), capaces de despertar respuestas emocionales en su audiencia. Por ejemplo, activistas en contra de la prostitución y la trata de personas con fines de explotación sexual se expresaban de esta manera en una red social:

La prostitución ¿a quién beneficia? Evidentemente que a las mujeres no, ni al conjunto de la sociedad, beneficia al grupo de varones que se consideran con derecho a acceder a los cuerpos de aquellas mujeres y otras personas a quienes el patriarcado ubicó en ese lugar, sólo porque esos varones tienen mayor poder social y de género.

¿En qué beneficia a las mujeres heterosexuales que sus novios, amantes, compañeros, maridos vayan a los prostíbulos ahora llamados las cooperativas de "trabajo sexual" a eyacular sobre bocas, vaginas o anos o la parte del cuerpo que se les ocurra de mujeres y niñas, así como de travestis, transexuales y transgéneros, legitimando esta conducta diciendo que van a proporcionar trabajo ${ }^{10}$

También en otros espacios 
aparecen estas narrativas, como en los fundamentos de proyectos de ley que penalizan a los clientes de la prostitución:

Quiero volver a los conceptos básicos. Prostitución. ¿Qué es? Es el uso del cuerpo de una mujer por parte de un hombre para tener sexo, el paga dinero, él hace lo que él quiere. El minuto en el que te alejas de qué es realmente, te alejas de la prostitución y te adentras en el mundo de las ideas. Te sentirás mejor; pasarás un mejor momento; es más divertido; hay muchísimo para discutir, pero estarás discutiendo ideas, no, prostitución. La prostitución no es una idea. Es la boca, la vagina, el recto, penetrados usualmente por un pene, a veces por manos, a veces por objetos, por un hombre y luego por otro, y luego por otro, y luego por otro, y luego otro. Eso es lo que es.

Andrea Dworkin ${ }^{11}$ en Rodríguez, Marcela V. Tramas de la prostitución y la trata con fines de explotación sexual, Documentos de Trabajo, 84, Centro Interdisciplinario para el Estudio de Políticas Públicas, Diciembre $2012^{12}$.

Lo que es evidente aquí es el uso de imágenes sensoriales que apelan al disgusto como forma de movilizar emocionalmente una audiencia.

Además de emplear un lenguaje provocativo y hacer uso de narrativas chocantes, los discursos de los pánicos sexuales suelen presentar fuertes cargas valorativas (Irvine, 2006). Si bien la condena moral hacia las trabajadoras sexuales y el mundo del sexo comercial no resulta novedosa, la asociación lineal entre prostitución y trata ha llevado a una profundización de la misma (invisibilizando las voces de las trabajadoras sexuales y el hecho de que la prostitución a título personal no es delito en nuestro país).

A propósito de estas cuestiones, recuerdo una reunión de la legislatura de la Ciudad de Buenos Aires para debatir sobre prostitución y políticas públicas en la que una periodista expuso sobre los volantes de la prostitución:

Sra. Peker.- Buenos días. Soy periodista y trabajo sobre el tema de género. Vengo de un noticiero. Si en las calles hubiera afiches que dijeran: "Me ofrezco para matar a sueldo" o "vendo paco", sería un escándalo, una noticia. No entiendo cómo no es noticia la cartelería que todos podemos ver cuando salimos de acá o cuando transitamos por Corrientes y Suipacha. Un sábado, hace quince días, cuando salía de un programa de Radio Nacional con el fotógrafo Salvador Batalla, que está aquí presente, pudimos ver que la ciudad estaba poblada de los afichitos que vemos todos, que son ilegales y que además conducen, se tenga la postura que se tenga sobre la prostitución, a la explotación sexual sin ninguna duda.

\section{(...)}

Sra. Peker.- Quiero saber si ante esta nueva invasión, que se produce desde hace dos o tres años, no sería bueno que haya una reglamentación especial para los cartelitos que promocionan prostitución. Por ejemplo, si hay profesores de guitarra que promocionan su enseñanza a través de papeles, eso no sería perjudicial para la sociedad (11 de mayo de 2011. Comisión de Mujer, Infancia, Adolescencia y Juventud. Versión Taquigráfica) $)^{13}$.

Construidos con estos elementos (narrativas chocantes, datos falsos o no comprobados, valoraciones negativas, producción de miedo y énfasis en el peligro), los pánicos sexuales son fomentados y reproducidos principalmente por los medios masivos de comunicación.

Los ejemplos traídos muestran cómo los pánicos nos interpelan emocionalmente a través del uso de una instantánea con la que difícilmente se pueda no empatizar: peligro, secuestro, violencia sobre los cuerpos. ¿Quién podría no estar en contra de semejante "flagelo"?

Ahora bien, resulta que, como bien señalan Cohen (2002) e Irvine (2006), los pánicos sexuales también demonizan grupos de personas. $Y$ aquí viene algo interesante, bien se podría demonizar a los proxenetas, tratantes y policías que hacen de la prostitución otra "caja policial", y si bien estos personajes sociales son públicamente condenados, en la práctica más cotidiana de esta micropolítica emocional, la demonización, la construcción de la desviación, parece ir dirigida a otros personajes.

Últimamente son los clientes del sexo comercial los que han sido objeto de esta demonización, señalados como prostituyentes, o "violadores sistemáticos" al decir, por ejemplo, de Eva Giberti. ${ }^{14}$

Cuando empecé a investigar sobre esta temática el término prostituyente me pareció interesante porque creía yo que era importante para señalar la existencia de un mercado del sexo y por lo tanto de una demanda -ya que el cliente era siempre invisible. Y me parecía también que era forzar la reflexión sobre los estigmas tan desigualmente distribuidos. Pero, más tarde que pronto, me di cuenta de la carga valorativa que conlleva el término y cómo, además, es una definición que impide ver la variabilidad y diversidad de situaciones.

Es importante visibilizar y problematizar la existencia de una demanda dentro de un mercado sexual amplio pero aquí ha sido visibilizada para integrarla a propuestas represivas: 
Proyecto de penalización del cliente de Marcela Rodríguez:

ARTÍCULO $1^{\circ}$. - Incorpórase como artículo 126 bis del Código Penal el siguiente texto:

"Artículo 126 bis.- Será reprimido con prisión de seis (6) meses a tres (3) años el que ofreciere o entregare una suma de dinero o una cosa apreciable en dinero o provecho económico o cualquier tipo de beneficio por el uso sexual de una persona.

Lo dispuesto en el párrafo anterior es aplicable también en el caso de que el pago del dinero o la entrega de la cosa apreciable en dinero o beneficio sea realizado por una tercera persona. En ningún caso son punibles por la comisión de este delito las personas prostituidas." tes:

O discursos estigmatizan-

- ¿Por qué un varón paga por sexo?

-Paga para denigrar a la mujer y reforzar estereotipos tradicionales que puede ver en peligro.

(...)

- ¿Al cliente de prostitución le preocupa si con quien tiene sexo pago es víctima de trata?

- Definitivamente no. El cliente de prostitución es un varón que sabe muy bien que esas mujeres son esclavas y víctimas de trata. (Página 12, 27 de mayo de 2013. Entrevista a Juan Carlos Volnovich). ${ }^{15}$

Estas operaciones discursivas asumen un universo monolítico, como si los clientes del sexo comercial fuesen un cuerpo homogéneo. Es un discurso que desconoce la intersección de las esferas de la economía y de la intimidad, y hasta refuerza la distinción público-privado como entes separados. Es un discurso que permite avalar la idea de una sexualidad gratuita en el marco de una relación, preferentemente heterosexual y monogámica; si es en el marco del matrimonio, mejor.

Los pánicos estigmatizan. Pareciera que no hay sexualidades a ser exploradas y pensadas, no hay pregunta sino respuesta prefabricada: "hay violación sistemática, hay denigración." Por otra parte, al situar el temor sexual en una supuesta sexualidad masculina "natural", la construcción social del deseo sexual masculino como algo intrínseco, incontrolable y fácilmente excitable conlleva casi necesariamente la constricción del deseo sexual de las mujeres. Como sugiere Vance (1989), si ese deseo es el que desencadena la violencia sexual masculina, ese deseo no puede expresarse públicamente y queda confinado al matrimonio. Volvemos a la construcción de la "buena" y la "mala" mujer.

Luego nos encontramos con la demonización de las trabajadoras sexuales. Aquellas que se niegan a ser consideradas víctimas y/o las que reivindican sus derechos laborales terminan siendo vistas como cómplices o artífices. Se cuestiona la autonomía y la agencia de estas personas, se cuestiona sus decisiones, sus opciones y su militancia en pos de mejores condiciones de vida. Se las acusa de tener "discursos armados por los proxenetas", de "hablar por ellos"16, se las describe incapaces de tener voz propia.

La cruzada contra los volantes de la prostitución como símbolo de la explotación sexual, por ejemplo, es también la condena a la práctica del sexo comercial y a las trabajadoras sexuales porque no deja de poner en cuestión a aquella que voluntariamente pone sus papelitos como forma de publicitarse.

Esta demonización me parece particularmente complicada e injusta porque al ensalzar a la víctima forzada y demonizar a la trabajadora sexual que ha optado por esta actividad seguimos reproduciendo la división entre mujeres buenas y malas, la santa y la puta, la que merece ser reconocida y la que no.

La demonización, la construcción de los demonios populares o de los desviados, estigmatiza y, en estos casos de pánicos sexuales, se estigmatiza además en relación con la sexualidad. Porque ¿en qué lugar se pone a las personas que participan voluntariamente de la industria del sexo si el supuesto es que algunos actos sexuales son tan desagradables que nadie en su sano juicio accedería a realizarlos? Finalmente se trata de "sexualidades buenas y sexualidades malas", deseos sexuales posibles y deseos prohibidos.

\section{Los legados}

Los pánicos sexuales dependen de estas performances públicas para despertar respuestas emocionales en sus audiencias $y$, sin duda alguna, dependen de los medios de comunicación que son los que actúan como fuerza ígnea que generalmente realimenta el pánico y sensacionaliza los hechos. Es este clima emocional el que permite, a través de un discurso del miedo y victimista, atacar otros derechos al tiempo de convertir a cualquier voz disidente en chivo expiatorio o demonio popularfolk devil.

En este marco, legislaciones y políticas represivas son los legados más comunes de los pánicos morales. El pánico moral subraya la relación entre lo que se construye como acto desviado (la desviación) y las reacciones de las instituciones y agencias de control social. Cuando se trata de pánicos 
sexuales, dejan legislaciones represivas y definiciones normativas acerca de la sexualidad, disponen las eróticas permisibles y deseables.

En esta línea, hoy podemos ver una serie de políticas dirigidas contra de la trata de personas con fines de explotación sexual que criminalizan, en verdad, el ejercicio de la prostitución. Por ejemplo:

-Decreto 936/11 de prohibición de publicación de avisos de oferta sexual

-Cierre en municipios provinciales de cabarets, whiskerías y locales de alterne

-Recomendación de la Procuración General de la Nación que exhorta a los fiscales a iniciar investigaciones proactivas en supuestos de la ley 12.331 vinculándolos linealmente a la trata de personas, con el consecuente aumento de:

Allanamientos repetidos en los mismos domicilios

Allanamientos engañosos o ilegales y clausura de domicilios particulares.

"Rescate" de mujeres con el decomiso de sus pertenencias (dinero, celulares) que nunca o pocas veces son devueltas

-Requisito de Visa para las migrantes provenientes de República Dominicana

-Modificación de la ley de trata (diciembre 2012) que trajo aparejada la indistinción entre prostitución forzada y prostitución voluntaria

-Proyectos de penalización del cliente de prostitución y/o trata presentados durante el 2013 en Diputados (Proyecto Rodríguez) y Senadores (Proyecto Fernández) que provocarían un aumento de la clandestinización y la vulneración de los derechos humanos de Ixs trabajadorxs del sexo así como la estigmatización de éstos y los clientes.
Una serie de políticas, en definitiva, que habilitan la vulneración concreta y cotidiana de los derechos de las trabajadoras sexuales (Daich y Varela, 2013). Claramente, estas políticas no responden solamente al pánico sino también a políticas e intereses concretos de Estado en coyunturas político-económicas concretas. $Y$ a ellos hay que sumarle las agendas de los organismos internacionales y las formas en que éstas operan en la política local.

Quiero prestar especial atención aquí a uno de estos legados del pánico sexual y que tiene que ver con estas políticas de erradicación de la publicidad de la oferta sexual ya sea en los medios masivos de comunicación, ya sea en las calles.

Tenemos por un lado el decreto presidencial 936/2011 (conocido popularmente como "prohibición del rubro 59") que recogió algunas demandas del movimiento de mujeres y que fue lanzado con el objetivo tanto de eliminar las expresiones discriminatorias referidas a las mujeres, como de luchar contra la trata de personas. El decreto creó una oficina que monitorea la presencia de avisos de oferta y demanda de sexo comercial, y que se ha ocupado de exigirle a grandes periódicos que eliminen avisos que promueven la oferta sexual. Comenzaron por los avisos que lo hacían de manera ostensible y con contenidos que podemos discutir, como por ejemplo:

Chilenita dulce, fogosa natural, 130-60-95

Estos avisos de diarios así como los volantes de la prostitución que pululan por toda la ciudad han sido criticados, por ejemplo en la red Rima ${ }^{17}$, resaltando que: son ofensivos para todas las mujeres, por la fragmentación y mercantilización de los cuerpos (sólo exponen colas y pechos de tamaños imposibles sin intervenciones o cirugías), por los estereotipos ("blancas", "paraguayitas"), por la presentación de las mujeres como absolutamente disponibles para la voluntad sexual de los varones ("todas tus fantasías")

Ahora bien, creo que es importante diferenciar entre la crítica al sexismo presente en la industria del sexo y la erradicación de la industria del sexo. ¿Se trata de eliminar las expresiones discriminatorias y ofensivas o de eliminar la industria del sexo?

Como señalaba, la oficina de monitoreo comenzó atendiendo a estos avisos explícitos pero se encarga también de los que considera engañosos como Masajistas ("Masajes, relax, absoluta reserva"), o "Srta. 21 años busca señor." Obviamente, luego de la promulgación del decreto, las trabajadoras sexuales dejaron de publicar en lo que se conoce como el rubro 59 y empezaron a hacerlo como masajistas o en "solos y solas". El ejercicio de la prostitución a título personal no está prohibido en este país pero ahora sí está prohibido ofrecer un servicio sexual a través de un clasificado en un diario.

En consonancia con esta política, distintas acciones, muchas protagonizadas por agrupaciones feministas y otras no, se dirigieron contra la publicidad de la oferta sexual en la vía pública, los famosos papelitos o volantes de la prostitución. No me interesa abordar aquí las acciones de la Campaña Abolicionista ni de otras organizaciones feministas sino prestar atención a unas iniciativas de la ciudad que vienen ligadas al PRO.

En diciembre del año 2012 se aprobó un proyecto presentado por la legisladora de la ciudad 
por el PRO, Gabriela Seijo, que prohíbe estos volantes:

\section{Ley 4486}

Fundamentos del proyecto:

El presente proyecto de ley tiene por objeto determinar la prohibición en la Ciudad de Buenos Aires, de toda publicidad que en forma explícita o implícita comporte la oferta de servicios sexuales, o de establecimientos donde estos servicios sean desarrollados y/o facilitados; así como de todo volante que fuera entregado, distribuido o colocado en la vía publica con idénticos fines.

Busca este proyecto no solamente contribuir a la lucha contra la explotación sexual, la violencia contra las mujeres y la trata de personas, sino asimismo erradicar de las calles de la ciudad, toda imagen que por su contenido sexual -explícito o implícito- atente contra la dignidad de la mujer, y el derecho de los ciudadanos a disfrutar de un ambiente urbano libre de imágenes vejatorias.

Así, los volantes de la oferta sexual, ya sean explícitos o implícitos, están hoy prohibidos en la Ciudad de Buenos Aires porque lo que se busca erradicar no son las "imágenes vejatorias" sino el sexo comercial. La industria del sexo refleja las desigualdades, las jerarquías y el sexismo imperante en la sociedad en su conjunto (Rubin, 2011) por lo que no ha de extrañarnos que su propaganda reproduzca esas diferenciaciones y desigualdades. Nuevamente cabe diferenciar entre analizar y oponerse a las manifestaciones de desigualdad sexual específicas de la industria del sexo y los intentos de eliminar el sexo comercial. ¿Por qué es más peligrosa esa imagen de contenido sexual que una propaganda de Mr. Músculo? ${ }^{18}$

Un poco como respuesta a estas políticas, un poco por procesos y gustos personales, algunas trabajadoras sexuales comenzaron a volantear con papelitos sin contenidos sexuales explícitos (caricaturas de Cupido, el conejito de Playboy, Betty Boop, dibujos naive, etc.). Incluso algunos de estos volantes traen la leyenda: "trabajo sexual no es igual a trata". Pero todos estos volantes también caen dentro de lo prohibido porque serían "promoción implícita de la oferta sexual" según la nueva ley.

Después del fallo del caso Marita Verón, una ONG Ilamada Mujeres como vos, cuyas integrantes están ligadas al PRO, empezó a organizar lo que denominaron Martes Rojos. Se trata de encuentros en la ciudad de Buenos Aires para, munidas de bolsas de residuos rojas, limpiar las calles de los volantes con oferta sexual:

Se denomina martes rojos porque la primera vez que se llevó a cabo fue un martes y rojos en alusión a las bolsas de residuos patológicos de los hospitales dado que es así como nos sentimos las mujeres, tratadas como descarte y objeto" afirmó Carolina Barone, presidenta de la ONG Mujeres como vos y agrega "Hacemos esto por todas las mujeres víctimas de explotación sexual en el mundo, para no olvidar a Marita Verón y seguir ratificando nuestro compromiso diario contra este flagelo que ya dejó 700 mujeres desaparecidas en Argentina y miles más que potencialmente pueden estar envuelta en estas redes.

En la última sesión de la Legislatura Porteña de 2012, se aprobó en forma unánime un proyecto de ley de la Diputada Gabriela Seijo (PRO) que sanciona con multas de hasta 83 mil pesos a todas las partes de la cadena de promoción de servicios sexuales, desde quien promociona servicios sexuales hasta la persona que pega folletos, pasando por quien imprime el material gráfico, esta ley aprobada fue reglamentada por el Jefe de Gobierno Mauricio Macri y publicada en el Boletín Oficial de la Ciudad el pasado mes de febrero. (Gacetilla de prensa de Mujeres como Vos)

La presidenta de la ONG, Carolina Barone, decía en una entrevista:

Es una misión casi imposible. Si podés fijate y te vas a dar cuenta: ya no ponen siluetas de mujeres, sino conejitas o una manzanita mordida... No, no es un triunfo nuestro, pero estos tipos son conscientes de que los estamos siguiendo y sacando fotos. ${ }^{19}$

Las mujeres organizadas en esta asociación realizan también "Sábado Rojo" en el barrio de Belgrano, "Recoleta Roja", "Once Rojo". Llevan adelante esta actividad en distintos barrios y en ocasiones cuentan con invitados tales como actores o legisladores PRO.

Los argumentos emocionales son poderosas herramientas de las políticas morales, las imágenes sensoriales movilizan audiencias ¿qué son las bolsas rojas? Residuos patológicos: la trata, la prostitución forzada... ipero ese es el lugar que le están asignando también a las trabajadoras sexuales! Porque el pánico sexual, que tiene algo de contaminación social también, no explica ni describe, juzga y condena. No importa si el papelito es efectivamente indicio de trata, de explotación o de trabajo sexual autónomo o consentido, el mensaje es que la prostitución es moralmente indeseable.

\section{Palabras finales}

Para terminar, quería recordar y subrayar que las cruzadas morales son siempre peligrosas para los intereses de nosotras, 
las feministas. Alianzas de los feminismos con fuerzas conservadoras, de las más antifeministas, ya han ocurrido en el pasado. $\mathrm{Y}$ que hoy el PRO, a través de la diputada Seijo y de la ONG Mujeres como Vos (cuya presidenta es la esposa del diputado PRO Garayalde), que esta fuerza política actúe en nombre de algunas reivindicaciones del feminismo es, por lo menos, preocupante. Que el PRO que ha estado en contra del matrimonio igualitario, que ha vetado la ley de aborto no punible y otras tantas, pueda hoy potencialmente aliarse con un sector del feminismo es preocupante.

El Pánico sexual triunfa cuando crea un clima político emocional tal que es imposible hablar de sexo por fuera del paradigma del sexo como peligro. Por lo que, a más de 30 años de la Conferencia de Barnard cabe recordar la propuesta de Carole Vance (1989) para quien la sexualidad es simultáneamente campo de limitaciones, represión y peligro, a la vez que de exploración, placer y actuación humana. Este doble enfoque es importante porque hablar sólo de placer es ignorar la estructura patriarcal en que vivimos y porque hablar sólo de peligro, violencia y opresión es ignorar la experiencia de las mujeres como agentes de sexualidad con opciones sexuales (1989: 9).

El pánico sexual, con su producción de miedo y alerta, no despolitiza, todo lo contrario. El desafío es poder generar arenas políticas donde todas las narrativas sean audibles, donde haya espacio para otros discursos, principalmente el de las protagonistas.

Notas:

* Este trabajo ha sido realizado en el marco del proyecto del FONCyT, PICT 20110420: "Género como estructura de violencia y poder: policía y prostitución". Una primera versión fue expuesta en la Mesa redonda Reflexiones Actuales sobre Prostitución organizado por el PRI Teoría Feminista en el IIEGE/UBA.

1 Pánico moral es una caracterización que le ha servido a las ciencias sociales para dar cuenta de fenómenos generalmente asociados al control de las clases populares pero como conceptualización ha sido utilizada también en análisis tan disímiles como las migraciones de principios del siglo XX o la caza de brujas de la Inquisición.

El pánico moral a fines del siglo XIX fue una respuesta a los cambios, en nuestro país a la inmigración, que desestabilizaba un mundo supuestamente apacible y conservador, al traer lo diferente, y además las luchas sindicales. El peligro venéreo, los niños en las calles, la prostitución.

2 Traducción propia.

3 Barnard Conference on Sexuality de 1982, Universidad de Columbia. Fue un encuentro que propuso ir más allá de los debates sobre pornografía y violencia y de las propuestas de los grupos anti pornografía, quienes se opusieron a este encuentro y hasta lo boicotearon. De este encuentro participaron académicas feministas reconocidas como Ellen Dubois, Gayle Rubin, Ellen Willis, Carole Vance, entre tantas otras. A partir de entonces se dice que comienzan las Sex Wars, las "guerras del sexo" que se traducen en distintas conceptualizaciones feministas respecto del sexo y la sexualidad y sus relaciones con la violencia y el género.

4 Estas apreciaciones fueron vertidas por Aguer en un documento "Orientaciones oficiales sobre educación sexual" del 27 de julio de 2009 que puede consultarse aquí: http://www.aica.org/aica/documentos_files/Obispos_Argentinos/ Aguer/2009/2009_07_27.html

5 http://www.migraciones.gov.ar/pdf_varios/campana_grafica/pdf/nopermitasqueabusendevos.pdf. De modo similar, la Red Nacional Alto al Tráfico y la Trata (RATT) lanzó el año pasado una campaña gráfica que dicta: "Podría ser: Tu hija, tu hermana o la madre que te parió."

6 A partir del secuestro y asesinato de su hijo en 2004, Blumberg hizo su aparición en la arena pública organizando marchas contra la inseguridad y pugnando por el endurecimiento de las leyes penales. En agosto de ese mismo año, se modificó el código penal para aumentar las penas en algunos delitos contra las personas, reforma que se conoció como "leyes Blumberg."

7 Por ejemplo, http://violenciaytrata.savethechildren.es/docs/Docs/27/3.pdf

8 Hasta el año pasado al menos, los medios de comunicación reproducían el número de 700 mujeres desaparecidas secuestradas por redes de trata, número 
ofrecido por la ONG La Casa del Encuentro. Este número no constituye una cifra oficial ni un dato confiable. Así, resulta de un contraste llamativo que mientras los medios insisten con más de 700 desaparecidas, la muestra "Todas las mujeres presentes" organizada en abril de 2013 en la ex Esma reunía la historia de tan solo 11 niñas y mujeres víctimas de redes de trata. $Y$ cabe mencionar además que no todas estas 11 tristes historias pueden vincularse fehacientemente con el delito de trata (o al menos no ha sido probado en sede judicial y/o ha sido hipótesis de investigación judicial).

9 Zaida Gatti es la titular del Programa Nacional de Rescate y Acompañamiento a las Personas Damnificadas por el Delito de Trata del Ministerio de Justicia de la Nación http://www.pagina12.com.ar/diario/elpais/1-176026-2011-09-04.html

10 El resaltado es mío aquí y en todas las citas que siguen.

11 Andrea Dworkin fue una de las principales voceras del movimiento antipornografía norteamericano.

12 Este trabajo forma parte de los Fundamentos del proyecto de ley de penalización de clientes de la prostitución que la diputada Marcela Rodríguez presentó en abril de 2013.

13 En dicha reunión se encontraban presentes integrantes de la Asociación de Mujeres Meretrices de la Argentina, quienes respondieron a estas apreciaciones dando cuenta del hecho de que muchas de sus compañeras publicitaban sus servicios a través de estos volantes y que ellas no se consideraban "perjudiciales para la sociedad".

14 http://www.eleco.com.ar/noticias/Inter\%C3\%A9s-General/42508:4/Eva-Giberti:La-trata-existe-porque-hay-hombres-que-son-violadores-sistem $\% \mathrm{C} 3 \% \mathrm{~A} 1$ ticos-. html

15 http://www.pagina12.com.ar/diario/sociedad/3-220888-2013-05-27.html SOCIEDAD

$16 \mathrm{http}: / /$ www.cronistasao.com.ar/socie-contra-la-trata-de-personas-.htm

17 Rima es una lista de correo electrónico dedicada al intercambio de información entre mujeres feministas, organizaciones de mujeres, investigadoras, activistas, estudiantes, etc.

18 Las propagandas de Mr. Músculo, como las de todos los productos de limpieza, suelen reproducir los estereotipos tradicionales acerca de los roles de género que asignan a las mujeres el espacio de lo doméstico (lo privado, la familia) y reservan para los varones la gestión del espacio público (como la política por ejemplo).

19 http://parabuenosaires.com/carolina-barone-la-esposa-del-legislador-pro-garayalde-logro-tener-su-pagina-en-clarin/ 26/3/2013

\section{Bibliografía:}

COHEN, Stanley. (2002) [1972] Folk devils and moral panics: The creation of the mods and the rockers. London, Routledge.

DAICH, Deborah y VARELA, Cecilia. (2013). "Entre el combate a la trata y la criminalización del trabajo sexual: las formas de gobierno de la prostitución". En evaluación en Delito y Sociedad.

DUGGAN, Lisa y HUNTER, Nan (2006). Sex Wars: sex dissent and political culture. New York, Routledge.

IRVINE, Janice. (2000). "Doing it with words: discourse and the sex education culture wars", en Critical Inquiry 27. Pp.58-76

(2006). "Emotional scripts of sex panics" en Sexuality Research \& Social Policy. Vol.3, n 3. Pp. 82-94

RUBIN, Gayle. (2011). Deviations: A Gayle Rubin Reader. Durham, Duke University Press.

VANCE, Carole. (1989). "El placer y el peligro: hacia una política de la sexualidad". En: Vance, Carole (comp.). Placer y peligro. Explorando la sexualidad femenina. Madrid, Ed. Revolución.

VARELA, Cecilia. (2011). La producción de estadísticas en relación a la trata de mujeres vinculada al comercio sexual, Ponencia presentada en el X CAAS, Universidad de Buenos Aires.

. (2013). Los números de la trata. Ponencia presentada en las VI Jornadas de investigación en Antropología social, FFyL-UBA. 